\title{
Dynamic Changes in Circulating Plasma B-type Natriuretic peptide levels and its Influencing Factors in Patients with Hemorrhagic Fever with Renal Syndrome
}

\section{Ning Ma}

First Affiliated Hospital of Harbin Medical University

Yongguo Li ( $\square$ liyongguodoctor@163.com )

Yanxin Huang

First Affiliated Hospital of Harbin Medical University

Mingyan Xu

First Affiliated Hospital of Harbin Medical University

\section{Yue Zhao}

First Affiliated Hospital of Harbin Medical University

\section{Shupeng Song}

First Affiliated Hospital of Harbin Medical University

Lisheng Jiang

First Affiliated Hospital of Harbin Medical University

\section{Yinghua Lan}

First Affiliated Hospital of Harbin Medical University

\section{Research article}

Keywords: hemorrhagic Fever with Renal Syndrome, hantavirus, B-type natriuretic peptide, influence factor

Posted Date: August 13th, 2020

DOI: https://doi.org/10.21203/rs.3.rs-52331/v1

License: @ (i) This work is licensed under a Creative Commons Attribution 4.0 International License. Read Full License 


\section{Abstract}

Background: Typically, Hemorrhagic fever with renal syndrome (HFRS) occurs in five sequential stages: Febrile, hypotensive, oliguric, polyuria, and convalescent stage. The pathophysiological process involves the release of inflammatory mediators, the fluctuation of blood volume and the injury of the Multiple organs, and all the factors mentioned above may cause the elevation of the level of plasma B-type natriuretic peptide (BNP). In addition, the physiological effects of BNP in regulating blood volume and promoting angiogenesis may in theory alleviate the pathological state of HFRS. So, this study is to explore the clinical application of BNP in HFRS by dynamically monitoring the BNP levels and analyzing the factors associated with BNP expression.

Methods: Eighty-six in-patients with HFRS were divided into the mild, moderate and severe groups according to disease severity. Mixed-effects linear model was used to analyze the differences in BNP expression according to disease severity and disease stage. The factors affecting BNP expression were analyzed using a linear regression model for each disease stage.

Results: BNP showed dynamic changes that corresponded with disease progression. The more severe the disease, the overall BNP level was higher. Disease severity, neutrophil count and pulse pressure were independent factors for BNP, while cardiac injury related indicators were not.

Conclusions: In HFRS the main factors promoting BNP expression were inflammation and blood volume, rather than heart disease. BNP can be regarded as an index for judging the severity of the disease and guiding body fluid treatment.

\section{Background}

Hemorrhagic fever with renal syndrome (HFRS) is a zoonosis caused by different species of hantaviruses including Hantaan virus (HTNV), Seoul virus (SEOV), Puumala virus (PUUV) and Dobrava/Belgrade virus (DOBV/BGDV), each of which causes diseases with differing severity. HTNV may cause the most severe form of HFRS; PUUV is endemic in northern Europe and may cause a generally mild form of HFRS. China is the most seriously affected country which accounts for over $90 \%$ of the total HFRS cases around the world. During 1950-2014, a total of 1,625,002 cases were reported in China, with the death rate of $2.89 \%(1,2)$. Heilongjiang province ranked one of the highest levels of HFRS incidence in China, HFRS here was mainly caused by HTNV and SEOV (3). Hantavirus infection causes extensive damage in capillaries and small vessels via the release of vasoactive substances and inflammatory mediators (IL-1/6, TNF- $a$ and so on) $(1,4,5)$, additionally leading to fluctuations in blood volume, coagulation disorders and injury to body tissues and organs. Typically, HFRS occurs in five sequential stages: febrile, hypotensive, oliguric, polyuria, and convalescent. The polyuria stage is subdivided into a transitional stage, early stage, and late stage.

B-type natriuretic peptide (BNP) is a cardiac natriuretic peptide hormone that was identified in a recent study $(6,7)$. Its concentration in systemic circulation among the healthy population is approximately $3.5 \mathrm{pg} / \mathrm{ml}$, but its expression increases significantly in the presence of ventricular wall tension $(8,9)$, volume expansion $(10,11)$, inflammation cytokines (IL-1ß\TNF-a) $(12-15)$ tissue hypoxia $(16,17)$ and other stress factors. The physiological effects of BNP include diuresis, natriuresis, vasodilation, and inhibition of the renin-angiotensin-aldosterone system, which play crucial roles in the regulation of water and electrolyte homeostasis (18). In addition, BNP can stimulate endothelial progenitor cell proliferation and affect vascular growth and regeneration $(19,20)$.

We hypothesized that inflammatory mediators (IL1/TNF-a), increased blood volume, and hypoxia induced by tissue injury in the course of HFRS may stimulate BNP synthesis, and the physiological effects of BNP in regulating volume homeostasis and promoting angiogenesis may reduce volume load and repair extensive vascular damage in HFRS. Therefore, the study of plasma BNP has important clinical significance for HFRS. Elevated plasma BNP levels in PUUV 
infection, Crimean-Congo hemorrhagic fever, and dengue infection have been reported in recent years, but these studies tested BNP only once throughout the course of the disease (21-25). However, the clinical characteristics in each stage of HFRS by HTNV and SEOV are significantly different, and the BNP level in a single session could not reflect the overall characteristics. Therefore, we have dynamically monitored the plasma BNP levels in different stages according to severity, and analyzed the factors associated with BNP expression, in order to explore the clinical application of BNP in HFRS.

\section{Methods}

\section{Study design}

We prospectively examined 86 patients with HFRS admitted to the Department of Infectious Diseases in the First Affiliated Hospital of Harbin Medical University between January 2014 and March 2015.From these 86 patients, we collected 241 plasma samples at the febrile, oliguric, transitional, early polyuria, and late polyuria stages of the disease.

In order to ensure that the samples were comparable, the collection time points for the samples were defined as follows: febrile stage: 1-3 days before the end of the stage; oliguria stage, transitional stage and early polyuria stage: the first 1-3 days of the course of the disease; late polyuria stage: later at the time of this stage and close to convalescent stage.

In this study all patients were by the clinical diagnostic criteria for HFRS. The exclusion criteria were: (1) less than 18 years of age; (2) chronic heart disease (coronary artery disease, cardiac failure, severe valvulopathy, and/or cardiomyopathy); (3) chronic renal failure; (4) known pulmonary hypertension, pulmonary embolism, or chronic obstructive pulmonary disease; and (5) diseases of the central nervous system (e.g., meningitis, brain abscess, and cerebral hemorrhage).

All the cases were discussed daily at multi-expert meetings, and clinical management decisions were made by a competent physician. The therapeutic schedule included rehydration, electrolyte regulation and, in some patients, abatement of fever and dialysis therapy. In some patients, sample collection was discontinued while they received treatment in the intensive care unit; they were returned to our department after their condition had stabilized and were included in the study again. Each patient's disease was classified as severe, medium, or mild according to the classification criteria for HFRS (26), Supplementary 1 (the severe and critical types described in the criteria were collectively termed "severe" in this study).

The study protocol was approved by the Ethical and Educational Committee of the First Affiliated Hospital of Harbin Medical University and conforms to the ethical guidelines of the Declaration of Helsinki. Patients or their Immediate family members provided their informed consent for the study. The trial has been registered under Clinical Trial Registry number chiCTR-COC-14005507 and can be found here: http://www.chictr.org.cn/edit.aspx?pid=9870\&htm=4 (Researching the clinical characteristics and pathogenesis of hemorrhagic fever with renal syndrome).

Plasma BNP measurement

Plasma BNP concentration was measured using a chemiluminescence microparticle immunoassay (Abbott I-2000 automated chemiluminescence apparatus, BNP detection reagents; Abbott, Abbott Park, IL, USA). Venous blood was collected in EDTA-containing plastic test tubes and centrifuged at $4000 \mathrm{rpm}$ for $5 \mathrm{~min}$. Following this, the plasmacontaining supernatant was collected for BNP measurement. The same laboratory technician performed the BNP tests within $2 \mathrm{~h}$ at room temperature. 
Basic clinical data were recorded for all patients, including age, sex, weight, comorbidities, symptoms, signs, clinical type, date of onset, and blood collection date. Blood pressure (pulse pressure = systolic pressure - diastolic pressure), heart rate, urine output, and body temperature were monitored daily. Neutrophil, creatine kinase-MB and creatinine clearance rate $([\{140-$ age $\} \times$ body weight $\{\mathrm{kg}\}] /[0.818 \times$ serum creatinine $\{\mu \mathrm{mol} / \mathrm{L}\} \times 0.85$ for women $])$ were measured at various stages of the disease. All blood samples were collected early in the morning (06:00-07:00), with the patient in the horizontal position. All the patients fasted for at least $8 \mathrm{~h}$ before blood collection.

Imaging of the abdominal cavity, chest, and heart was performed according to the patients' condition using echocardiography or electrocardiography (ECG). For ultrasound examination, a color Doppler ultrasound diagnostic (MyLab ${ }^{\mathrm{TM}}$ Twice; Esaote SpA, Genoa, Italy) was used. For cardiac examination, left ventricular ejection fraction (LVEF) was measured in the $\mathrm{M}$ mode, and the time-velocity integral method was used to measure peak blood flow velocity in the mitral valve in early diastole/late diastole (E/A). For 12-lead ECG recording, a Cardio Fax 3 system (Nihon Kohden, Tokyo, Japan) and a Wilson lead network were used, with the patient supine.

Statistical analysis

Continuous variables were expressed as mean standard deviation, and categorical variables were expressed as case numbers and percentages. Differences between groups were compared by analysis of variance for normally distributed variables, Wilcoxon rank-sum test for variables with a skewed distribution, and the chi-square test or Fisher's exact test for categorical variables. Mixed-effects linear model was used to analyze the differences in BNP expression according to disease severity and disease stage. The effect of clinical examination and laboratory indicators on BNP expression were analyzed using a linear regression model for each disease stage. Variables identified as significant $(P<0.05)$ in the univariate analyses were further screened in multivariate analyses. All statistical analyses were conducted using the SAS software (version 9.2), and a two-sided $P$ value of $<0.05$ was established as the level of statistical significance for all the tests.

\section{Results}

\section{Patient characteristics}

The clinical features of the patients are provided in Table 1. 241 samples were collected from 86 patients with HFRS. The reasons are as follows: This is due to two or three natural course overlaps in some severe patients and the lack of transitional stage in some mild patients; Some patients had missed the fever stage when they were hospitalized; In addition, 1 person abandoned treatment during the oliguria phase, and 5 people interrupted BNP testing due to treatment in ICU. $61.1 \%$ of severe received dialysis, while only $6.1 \%$ of moderate; Pulmonary edema occurred in 2 patients with severe disease.

The number of neutrophils, pulse pressure and creatinine clearance showed dynamic changes, and the change range was severe $>$ medium >mild. Pulse pressure was the highest and creatinine clearance was the lowest in the oliguria stage of severe HFRS and in the transition stage of moderate HFRS. During the febrile stage of severe and moderate patients, the creatinine clearance rate decreased significantly (Table 2).

Plasma BNP levels at different stages in patients with mild, medium and severe HFRS

The dynamic changes observed in the plasma BNP levels are shown in Figure 1, As the disease progresses, BNP levels gradually increase to reach a peak, and then decline as the disease improves. The peak of BNP levels was observed in 
the oliguric stage of patients with severe HRFS, in the transition stage of patients with moderate HFRS, and in the early polyuria stage of patients with mild HFRS. Comparison BNP levels between consecutive stages in HFRS are shown in Table 4. In addition, plasma BNP levels increased with increasing disease severity at the same stage (except during the febrile phase), with statistically significant differences, Table 3. After adjusting for age, sex, weight and dialysis, the severity and stage as well as their interactions had a significant effect on BNP levels, Table 5.

Factors influencing the expression of BNP in different stages of HFRS

Univariate linear regression analysis was used to examine the clinical parameters that may influence BNP expression in each stage of HFRS. Disease severity, neutrophil count, creatinine clearance rate, pulse differential pressure, E/A, and age were found to be significantly correlated with serial BNP measurements by univariate linear regression analysis $(P<$ 0.05) (Table 6). Sex, weight, heart rate, LVEF, abnormal ECG and Creatine kinase-MB findings were not correlated with BNP levels $(P>0.05)$ (supplementary 2). Multivariate linear regression analysis showed that the significant independent influencing factors affecting BNP were distinct in different stages, for example, the neutrophils count was significant in the febrile stage, while pulse pressure and disease severity were in the oliguric stage, disease severity was in the transitional stage, neutrophil count and disease severity were in the early polyuria stage, and the age was significant in the late polyuria stage (Table 6).

\section{Discussion}

These were the main findings of our study: (1) In HFRS patients, the more severe the disease, the overall BNP level was higher. (2) The BNP levels at different stages of HFRS showed dynamic changes that corresponded with disease progression. (3) Disease severity, neutrophil count, and changes in pulse pressure were the significant independent factors associated with the plasma BNP level, while Indicators related to cardiac injury was not.

This study showed that the BNP levels were significantly different between the different stages of HFRS, and the stage at which the peak BNP level was observed varied according to disease severity. Therefore, to discuss the clinical application of BNP in HFRS, plasma BNP level testing in every stage was more scientific value. This study is the first to investigate HFRS patients with Hantan and Seoul virus infections, and comprehensively describes significant influencing factors and the dynamic changes in BNP levels according to stage and severity.

The effect of renal function on BNP is widely concerned by doctors. BNP clearance is generally achieved by two routes, the most common one is binding to neutrophilic peptide chain endonuclease (NEP) on the membrane surface. In addition, BNP enters lysosomes through intracellular phagocytosis mediated by the receptor NPRC and then is degraded (27). Previous studies have suggested that BNP concentrations are strongly correlated with residual renal function (28, $29)$, but several subsequent studies have reported that BNP only has a $21-22 \%$ or lower dependence on renal function for its clearance (30-32). In this study, creatinine clearance was found to be associated with BNP, but it was not an independent influential factor. In the fever stage of severe and medium HFRS, the creatinine clearance rate was significantly reduced, but the level of BNP only slightly increased, which also indicated that the effect of creatinine clearance rate on BNP was very weak.

We focused on the correlation between heart injury and BNP in patients of HFRS (33). Heart rate, electrocardiogram, creatine kinase isoenzyme, LVEF, and E/A were used to assess cardiac status. Only E/F affects BNP level, but it is not an independent factor of BNP. The study suggests that heart damage is not the main cause of BNP elevation in HFRS. A report related to sepsis also showed that the main factor affecting BNP expression was not heart disease (33).

In this study, neutrophils were used as markers of inflammation. Proinflammatory cytokines IL-1 $\beta$ and TNF-a selectively increased the activity of BNP promoters, thereby regulating the expression of the myocardial BNP gene $(12,13)$. We did 
not further examine the cytokines (IL-1 $\beta$ and TNF- $\alpha$ ) in patients, because previous studies on inflammatory mediators of HFRS have been clear $(1,4,5)$. Pulse pressure were used as an indicator of blood volume changes. In the setting of volume expansion, the resulting wall stress can initiate the synthesis of BNP in the ventricular myocardium and, thus, cause an increase in the plasma BNP levels $(10,11)$. BNP, with a half-life of only $22 \mathrm{~min}$, can be used for real-time monitoring of blood volume changes. It has been widely used in the volume management of patients with heart failure in clinical practice. At present, no specific approved therapy is available for HFRS, the treatment is primarily supportive. Maintaining the fluid and electrolyte balance together with circulatory volume is very important to avoid dangerous over hydration. The results suggest that BNP can be used to monitor blood volume changes in HFRS, and doctors can adjust the fluid treatment regimen according to the change of BNP level, so as to reduce complications such as pulmonary edema and hypervolemia syndrome.

The main characteristic of the febrile stage is inflammatory reaction, while the tissue damage is relatively light and blood volume maintain normal or reduced. In this stage, the slight increase in plasma BNP levels observed in this study may be attributable to the inflammatory stimuli. As the disease progresses into the oliguric stage, patients with moderate and severe HFRS exhibit increased kidney damage, a significantly reduced urine output, significantly increased blood volume, and even pulmonary edema. These factors may result in significant increase of the observed BNP levels. The transitional stage is characterized by the transition from oliguria to polyuria. In this stage, although urine volume starts to increase, renal function is further decreased and blood volume continues to increase, leading to a further increase in the plasma BNP levels. In the present study, in patients with moderate HFRS, the plasma BNP levels peaked in this period. However, the peak value of plasma BNP levels in patients with severe HFRS was observed in the oliguric stage. This is probably because $61.1 \%$ of the patients with severe HFRS underwent hemodialysis. As a result of the hemodialysis treatment, their blood volume decreased rapidly and the concentration of some inflammatory mediators decreased. Therefore, their condition was alleviated in a short time and a rapid decline in their BNP levels was observed. During the early to late polyuria stage, organ function improved significantly and gradually returned to normal, with a decrease in blood volume, and a reduction in the inflammatory response. When the factors causing the elevation of BNP decreased, the BNP level would gradually reduce subsequently. The study reveals important information about the pathophysiological processes of HFRS associated with BNP. It can be seen that the pathophysiological changes of HFRS in each course of disease make BNP level significantly different. This suggests that clinicians must analyze BNP results in combination with the course of HFRS. In addition, BNP was involved in the maintenance of electrolyte homeostasis and promoted the regeneration of vascular cells, which may be an important part of the self-limiting mechanism in HFRS.

The higher the disease severity of HFRS is, the higher the BNP level will follow, and the severity independently affected the BNP level, which suggested that the plasma BNP level could be used as an indicator to evaluate the HFRS severity. Papanikolaou also found that disease severity, rather than infective cardiomyopathy, might be the main factor associated with elevated BNP levels in patients with severe sepsis (33). The study will be continued on the thresholds for determining disease severity at the early stages of HFRS. Vascular endothelial dysfunction is the basic pathological change, which determines the severity of HFRS. In clinical trials, intravenous type A natriuretic peptide (ANP) can improve pulmonary edema and reduce pulmonary vascular permeability in patients with acute lung injury $(34,35)$. An increase in the plasma BNP levels was found to accelerate vascular regeneration in a mouse of model of limb ischemia induced by femoral artery ligation (20). In addition, Recombinant human BNP (nesiritide) has produced satisfactory results in the treatment of heart failure (36). Therefore, natriuretic peptides may be an effective method to treat HFRS in the future.

\section{Conclusions}


In summary, this study provides comprehensive information about the dynamic changes in BNP levels that occur in HFRS according to clinical stage and severity of the disease, and the factors that influence plasma BNP levels. Based on our observations, BNP can be regarded as an index for judging the severity of the disease and guiding body fluid treatment; The main factors affecting BNP level in HFRS were not heart injury and creatinine clearance rate, while were blood volume and inflammatory mediators; In addition, BNP may be an important part of the self-limiting mechanism in HFRS. BNP plays a crucial role in the regulation of water and electrolyte homeostasis and the stimulation of vascular growth and regeneration, and future research should focus on whether it can be used to treat HFRS as well.

\section{Abbreviations}

Hemorrhagic fever with renal syndrome (HFRS); Hantaan virus (HTNV); Seoul virus (SEOV); Puumala virus (PUUV); Dobrava/Belgrade virus (DOBV/BGDV); B-type natriuretic peptide (BNP); electrocardiography (ECG); left ventricular ejection fraction (LVEF); neutrophilic peptide chain endonuclease (NEP); type A natriuretic peptide (ANP)

\section{Declarations}

\section{Ethics approval and consent to participate}

The study protocol was approved by the Ethical and Educational Committee of the First Affiliated Hospital of Harbin Medical University and conforms to the ethical guidelines of the Declaration of Helsinki. Patients or their Immediate family members provided their informed consent for the study. The trial has been registered under Clinical Trial Registry number chiCTR-COC-14005507 and can be found here: http://www.chictr.org.cn/edit.aspx?pid=9870\&htm=4 (Researching the clinical characteristics and pathogenesis of hemorrhagic fever with renal syndrome).

Consent for publication

Not applicable.

\section{Availability of data and materials}

The datasets generated and/or analysed during the current study are not publicly available but are available from the corresponding author on reasonable request.

\section{Competing interests}

The authors declare that they have no competing interests.

\section{Funding}

This study was funded by China Postdoctoral Science Foundation (20100471095) and Natural Science Foundation of China (30700700).

\section{Authors' contributions}

$N M, Y L$ and $Y L$ designed the study. NM, YL, YH, MX, YZ, SS and LJ collected, analyzed and interpreted the patient data. NM was a major contributor in writing the manuscript. All authors read and approved the final manuscript.

\section{Acknowledgements}

None. 


\section{References}

1. Jiang H, Du H, Wang LM, Wang PZ, Bai XF. Hemorrhagic Fever with Renal Syndrome: Pathogenesis and Clinical Picture. Front Cell Infect Microbiol. 2016;6:1.

2. Li CP, Cui Z, Li SL, Magalhaes RJ, Wang BL, Zhang C, et al. Association between hemorrhagic fever with renal syndrome epidemic and climate factors in Heilongjiang Province, China. Am J Trop Med Hyg. 2013;89:1006-12.

3. Zhang S, Wang S, Yin W, Liang M, Li J, Zhang Q, et al. Epidemic characteristics of hemorrhagic fever with renal syndrome in China, 2006-2012. BMC Infect Dis. 2014;14:384.

4. Vaheri A, Strandin T, Hepojoki J, Sironen T, Henttonen H, Makela S, et al. Uncovering the mysteries of hantavirus infections. Nat Rev Microbiol. 2013;11:539-50.

5. Wang PZ, Li ZD, Yu HT, Zhang Y, Wang W, Jiang W, et al. Elevated serum concentrations of inflammatory cytokines and chemokines in patients with haemorrhagic fever with renal syndrome. J Int Med Res. 2012;40:648-56.

6. Sudoh T, Kangawa K, Minamino N, Matsuo H. A new natriuretic peptide in porcine brain. Nature. 1988;332:78-81.

7. Glauser MP, Bonard. Treatment of experimental ascending Escherichia coli pyelonephritis with ceftriaxone alone and in combination with gentamicin. Chemotherapy. 1982;28:410-6.

8. Volpe M, Rubattu S, Burnett J, Jr. Natriuretic peptides in cardiovascular diseases: current use and perspectives. Eur Heart J. 2014;35:419-25.

9. Bursi F, Weston SA, Redfield MM, Jacobsen SJ, Pakhomov S, Nkomo VT, et al. Systolic and diastolic heart failure in the community. JAMA. 2006;296:2209-16.

10. McKie PM, Schirger JA, Costello-Boerrigter LC, Benike SL, Harstad LK, Bailey KR, et al. Impaired natriuretic and renal endocrine response to acute volume expansion in pre-clinical systolic and diastolic dysfunction. J Am Coll Cardiol. 2011;58:2095-103.

11. James KB, Troughton RW, Feldschuh J, Soltis D, Thomas D, Fouad-Tarazi F. Blood volume and brain natriuretic peptide in congestive heart failure: a pilot study. Am Heart J. 2005;150:984.

12. Ma KK, Ogawa T, de Bold AJ. Selective upregulation of cardiac brain natriuretic peptide at the transcriptional and translational levels by pro-inflammatory cytokines and by conditioned medium derived from mixed lymphocyte reactions via p38 MAP kinase. J Mol Cell Cardiol. 2004;36:505-13.

13. He Q, LaPointe MC. Interleukin-1beta regulation of the human brain natriuretic peptide promoter involves Ras-, Rac-, and p38 kinase-dependent pathways in cardiac myocytes. Hypertension. 1999;33:283-9.

14. Seto T, Kamijo S, Wada Y, Yamaura K, Takahashi K, Komatsu K, et al. Upregulation of the apoptosis-related inflammasome in cardiac allograft rejection. J Heart Lung Transplant. 2010;29:352-9.

15. Talha S, Charloux A, Enache I, Piquard F, Geny B. Mechanisms involved in increased plasma brain natriuretic peptide after heart transplantation. Cardiovasc Res. 2011;89:273-81.

16. Le Grand F, Rudnicki MA. Skeletal muscle satellite cells and adult myogenesis. Curr Opin Cell Biol. 2007;19:628-33.

17. Weidemann A, Klanke B, Wagner M, Volk T, Willam C, Wiesener MS, et al. Hypoxia, via stabilization of the hypoxiainducible factor HIF-1alpha, is a direct and sufficient stimulus for brain-type natriuretic peptide induction. Biochem J. 2008;409:233-42.

18. Clerico A, Giannoni A, Vittorini S, Passino C. Thirty years of the heart as an endocrine organ: physiological role and clinical utility of cardiac natriuretic hormones. Am J Physiol Heart Circ Physiol. 2011;301:H12-20.

19. Shmilovich H, Ben-Shoshan J, Tal R, Afek A, Barshack I, Maysel-Auslander S, et al. B-type natriuretic peptide enhances vasculogenesis by promoting number and functional properties of early endothelial progenitor cells. Tissue Eng Part A. 2009;15:2741-9. 
20. Kuhn M, Volker K, Schwarz K, Carbajo-Lozoya J, Flogel U, Jacoby C, et al. The natriuretic peptide/guanylyl cyclase-a system functions as a stress-responsive regulator of angiogenesis in mice. J Clin Invest. 2009;119:2019-30.

21. Wichmann D, Kularatne S, Ehrhardt S, Wijesinghe S, Brattig NW, Abel W, et al. Cardiac involvement in dengue virus infections during the 2004/2005 dengue fever season in Sri Lanka. Southeast Asian J Trop Med Public Health. 2009;40:727-30.

22. Miranda $\mathrm{CH}$, Borges Mde C, Matsuno AK, Vilar FC, Gali LG, Volpe GJ, et al. Evaluation of cardiac involvement during dengue viral infection. Clin Infect Dis. 2013;57:812-9.

23. Rasmuson J, Lindqvist P, Sorensen $\mathrm{K}$, Hedstrom M, Blomberg A, Ahlm C. Cardiopulmonary involvement in Puumala hantavirus infection. BMC Infect Dis. 2013;13:501.

24. Rajaniemi SM, Hautala N, Sironen T, Vainio O, Vapalahti O, Vaheri A, et al. Plasma B-type natriuretic peptide (BNP) in acute Puumala hantavirus infection. Ann Med. 2014;46:38-43.

25. Uysal EB, Sancakdar E, Seker A, Deveci K, Tuzcu N, Karapinar H. Alterations of serum brain type natriuretic peptide (BNP) in patients with Crimean-Congo hemorrhagic fever. Int J Clin Exp Med. 2015;8:2784-8.

26. Liu Z, Zhao Q, Han Q, Gao M, Zhang N. Serum thrombospondin-1 is altered in patients with hemorrhagic fever with renal syndrome. J Med Virol. 2008;80:1799-803.

27. Maalouf R, Bailey S. A review on B-type natriuretic peptide monitoring: assays and biosensors. Heart Fail Rev. 2016;21:567-78.

28. Takase H, Dohi Y. Kidney function crucially affects B-type natriuretic peptide (BNP), N-terminal proBNP and their relationship. Eur J Clin Invest. 2014;44:303-8.

29. Luchner A, Hengstenberg C, Lowel H, Riegger GA, Schunkert H, Holmer S. Effect of compensated renal dysfunction on approved heart failure markers: direct comparison of brain natriuretic peptide (BNP) and N-terminal pro-BNP. Hypertension. 2005;46:118-23.

30. Palmer SC, Richards AM. Does renal clearance differ between the B-type natriuretic peptides (BNP versus NTproBNP)? J Am Coll Cardiol. 2009;53:891-2.

31. van Kimmenade RR, Januzzi JL, Jr., Bakker JA, Houben AJ, Rennenberg R, Kroon AA, et al. Renal clearance of Btype natriuretic peptide and amino terminal pro-B-type natriuretic peptide a mechanistic study in hypertensive subjects. J Am Coll Cardiol. 2009;53:884-90.

32. Schou M, Alehagen U, Goetze JP, Gustafsson F, Dahlstrom U. Effect of estimated glomerular filtration rate on plasma concentrations of B-type natriuretic peptides measured with multiple immunoassays in elderly individuals. Heart. 2009;95:1514-9.

\section{Tables}

Table 1. Clinical features of patients with severe $(n=18)$, medium $(n=33)$, or mild $(n=35)$ hemorrhagic fever with renal syndrome 


\begin{tabular}{|c|c|c|c|c|}
\hline Variables & $\begin{array}{l}\text { Severe }(\mathrm{n} \\
=18)\end{array}$ & Medium $(n=33)$ & Mild $(n=35)$ & $P$ \\
\hline \multicolumn{5}{|l|}{ Basic information } \\
\hline Age $^{a}, y$ & $\begin{array}{l}47.1 \pm \\
10.9\end{array}$ & $41.0 \pm 12.2$ & $38.0 \pm 12.8$ & $<0.0001$ \\
\hline $\operatorname{Sex}(M / F)$ & $\begin{array}{l}14 \\
(77.8) / 4 \\
(22.2)\end{array}$ & $24(72.7) / 9(27.3)$ & $28(80) / 7(20)$ & 0.7722 \\
\hline Weight ${ }^{a}, \mathrm{~kg}$ & $\begin{array}{l}67.3 \pm \\
13.6\end{array}$ & $65.2 \pm 11.4$ & $67.8 \pm 10.9$ & 0.1054 \\
\hline \multicolumn{5}{|l|}{ Comorbidities } \\
\hline Pulmonary edema & $2(11.1)$ & 0 & 0 & \\
\hline Pancreatitis & $1(5.5)$ & 0 & 0 & \\
\hline Kidney rupture & $3(16.7)$ & 0 & 0 & \\
\hline Hepatitis B/cirrhosis & $1(5.5)$ & 0 & 0 & \\
\hline Colitis & 0 & 0 & $1(2.9)$ & \\
\hline Type 2 diabetes & $1(5.5)$ & $3(18.7)$ & 0 & \\
\hline Prosopalgia & 0 & 0 & $1(2.9)$ & \\
\hline EB virus infection & 0 & $2(6.1)$ & $2(5.7)$ & \\
\hline \multicolumn{5}{|l|}{ Clinical outcome } \\
\hline Improved & $16(88.9)$ & $33(100)$ & $35(100)$ & \\
\hline Dead & $1(5.5)$ & 0 & 0 & \\
\hline Discontinued therapy & $1(5.5)$ & 0 & 0 & \\
\hline \multicolumn{5}{|l|}{ Special treatment } \\
\hline Dialysis & $11(61.1)$ & $2(6.1)$ & 0 & \\
\hline $\begin{array}{l}\text { ICU comprehensive } \\
\text { treatment }\end{array}$ & $5(27.8)$ & 0 & 0 & \\
\hline \multicolumn{5}{|c|}{ Selective auxiliary examination results } \\
\hline $\begin{array}{l}\text { Hydrops (yes/no/no } \\
\text { data) }\end{array}$ & $\begin{array}{l}18 \\
(100) / 0 / 0\end{array}$ & $\begin{array}{l}19(57.6) / 3(9.1) / 11 \\
(33.3)\end{array}$ & $13(37.1) / 5(14.3) / 17(48.6)$ & 0.0001 \\
\hline Pleural effusion & $\begin{array}{l}14 \\
(77.8) / 3 \\
(6.7) / 1 \\
(5.6)\end{array}$ & $\begin{array}{l}11(33.3) / 13(39.4) / 9 \\
(27.3)\end{array}$ & $9(25.7) / 17(48.6) / 9(25.7)$ & 0.0054 \\
\hline Seroperitoneum & $\begin{array}{l}16 \\
(88.9) / 1 \\
(5.6) / 1 \\
(5.6)\end{array}$ & $\begin{array}{l}11(33.3) / 13(39.4) / 9 \\
(27.3)\end{array}$ & $7(20.0) / 11(31.4) / 17(48.6)$ & $<0.0001$ \\
\hline Pericardial effusion & $\begin{array}{l}6(33.3) / 11 \\
(61.1) / 1 \\
(5.6)\end{array}$ & $3(9.1) / 23(69.7) / 7(21.2)$ & $1(2.9) / 26(74.3) / 8(22.9)$ & 0.0284 \\
\hline
\end{tabular}




\begin{tabular}{|lllll|}
\hline ECG examination & $\begin{array}{l}9(50) / 3 \\
(16.7) / 6 \\
(33.3)\end{array}$ & $13(39.4) / 10(30.3) 10(30.3)$ & $17(48.6) / 9(25.7) / 9(25.7)$ & 0.8202 \\
\hline LVEF, \% & $61.6 \pm 2.3$ & $62.6 \pm 2.0$ & $64.3 \pm 3.2$ & 0.0235 \\
\hline E/A $(<1 />1)$ & $\begin{array}{l}14 \\
(77.8) / 2 \\
(11.1)\end{array}$ & $13(39.4) / 11(33.3)$ & $11(31.4) / 17(48.6)$ & 0.0149 \\
\hline $\begin{array}{l}\text { Sample numbers, } \\
\text { cases }\end{array}$ & 7 & 9 & & 14 \\
\hline Febrile stage & 14 & 10 & - \\
\hline Oliguric stage & 13 & 23 & 21 \\
\hline Transitional stage & 15 & 29 & 32 \\
\hline Early polyuria stage & 15 & 22 \\
\hline Late polyuria stage & 10 & 22 & 22 & \\
\hline
\end{tabular}

Notes: ${ }^{a}$ Normal distribution. Continuous data are expressed as the mean \pm standard deviation; categorical data are expressed as $n(\%)$. Mild HFRS did not manifest with an oliguria stage. LVEF, left ventricular ejection fraction; E/A, peak blood flow velocity in the mitral valve in early diastole/late diastole.

Table 2. Pulse pressure, heart rate, neutrophil count, and creatinine clearance rate at different stages of hemorrhagic fever with renal syndrome according to severity $(\mathrm{pg} / \mathrm{ml}) r \pm s$

\begin{tabular}{|llllll|}
\hline Variables & Disease stage & Severe & Medium & Mild & $P$ \\
\hline Pulse pressure & Febrile stage & $39.5 \pm 8.1$ & $39.9 \pm 6.7$ & $46.3 \pm 7.8$ & 0.0624 \\
\hline$(\mathrm{mm} \mathrm{Hg})$ & Oliguric stage & $56.6 \pm 13.8$ & $48.5 \pm 13.0$ & - & 0.0836 \\
& Transitional stage & $53.5 \pm 11.6$ & $49.5 \pm 15.8$ & $43.8 \pm 9.0$ & 0.1516 \\
& Early polyuria stage & $52.0 \pm 11.5$ & $47.9 \pm 14.0$ & $45.3 \pm 10.3$ & 0.3400 \\
\hline Neutrophil & Late polyuria stage & $43.4 \pm 9.0$ & $47.1 \pm 11.5$ & $44.4 \pm 9.4$ & 0.6681 \\
\hline count & Febrile stage & $22.1 \pm 8.2$ & $7.0 \pm 2.0$ & $4.5 \pm 6.4$ & $<.0001$ \\
\hline$\left(10^{9} / \mathrm{L}\right)$ & Oliguric stage & $6.9 \pm 2.3$ & $8.8 \pm 4.2$ & - & 0.3778 \\
\hline & Transitional stage & $7.1 \pm 6.0$ & $5.7 \pm 1.4$ & $4.8 \pm 4.8$ & 0.0105 \\
\hline Creatinine & Early polyuria stage & $5.7 \pm 3.4$ & $4.7 \pm 1.6$ & $4.0 \pm 2.4$ & 0.0287 \\
\hline clearance rate & Febrile stage & $19.7 \pm 13.8$ & $58.5 \pm 33.5$ & $99.0 \pm 38.5$ & $<.0001$ \\
\hline$(\%)$ & Oliguric stage & $10.1 \pm 4.0$ & $39.8 \pm 22.8$ & - & $<.0001$ \\
\hline & Transitional stage & $11.7 \pm 5.5$ & $33.5 \pm 26.0$ & $69.4 \pm 37.4$ & $<.0001$ \\
\hline & Early polyuria stage & $25.3 \pm 22.0$ & $45.2 \pm 27.9$ & $75.5 \pm 37.5$ & $<.0001$ \\
\hline & Late polyuria stage & $72.4 \pm 42.5$ & $74.8 \pm 31.5$ & $99.7 \pm 31.8$ & 0.0320 \\
\hline
\end{tabular}


Notes: Values shown are the mean \pm standard deviation. $\mathrm{P}<0.05$ indicates a significant difference between patients with severe, moderate, and mild HFRS. Mild HFRS did not manifest with an oliguric stage.

Table 3. B-type natriuretic peptide (BNP) levels at different stages of hemorrhagic fever with renal syndrome according to severity $(\mathrm{pg} / \mathrm{ml}) r \pm s$

\begin{tabular}{|lllll|}
\hline Course of disease & Severe & Medium & Mild & $P$ \\
\hline Febrile stage & $30.8 \pm 22.2$ & $13.9 \pm 6.7$ & $23.8 \pm 25.3$ & 0.0449 \\
\hline Oliguric stage & $1144.5 \pm 982.6$ & $110.8 \pm 187.4$ & - & 0.0007 \\
\hline Transitional stage & $916.5 \pm 659.2$ & $385.4 \pm 241.4$ & $89.6 \pm 100.6$ & $<.0001$ \\
\hline Early polyuria stage & $444.3 \pm 227.0$ & $285.1 \pm 185.5$ & $119.6 \pm 96.9$ & $<.0001$ \\
\hline Late polyuria stage & $93.9 \pm 101.8$ & $77.5 \pm 70.5$ & $44.9 \pm 76.1$ & 0.0064 \\
\hline
\end{tabular}

Notes: Values shown are the mean \pm standard deviation. $P<0.05$ indicates a significant difference in the BNP level between patients with severe, Medium, and mild HFRS. Mild HFRS did not manifest with an oliguric stage.

Table 4. Comparison of B-type natriuretic peptide (BNP) levels between different stages of hemorrhagic fever with renal syndrome

\begin{tabular}{|lllllll|}
\hline Type & $\begin{array}{l}\text { Comparison of BNP at different } \\
\text { stages }\end{array}$ & $F$ & $P$ & $\begin{array}{l}\text { Comparison of BNP at } \\
\text { different stages }\end{array}$ & $F$ & $P$ \\
Severe & Febrile stage vs. Oliguric stage & 65.11 & $<.0001$ & Oliguric stage vs. Transitional & 8.00 & 0.0053 \\
& Transitional vs. Early & 21.65 & $<.0001$ & Early vs. Later & 14.79 & 0.0002 \\
\hline Medium & Febrile stage vs. Oliguric stage & 0.43 & 0.5109 & Oliguric stage vs. Transitional & 8.08 & 0.0051 \\
\cline { 2 - 4 } & Transitional vs. Early & 2.00 & 0.1598 & Early vs. Later & 10.10 & 0.0018 \\
\hline \multirow{2}{*}{ Mild } & Febrile stage vs. Transitional & 0.48 & 0.4886 & - & 0.15 & 0.7005 \\
\hline & Transitional vs. Early & 0.15 & 0.7005 & Early vs. Later & 1.13 & 0.2902 \\
\hline
\end{tabular}

Notes: $P<0.05$ was considered to indicate statistical significance. "Transitional" refers to the transitional stage of the polyuria stage. "Early" refers to the early stage of the polyuria stage. "Late" refers to the late stage of the polyuria stage.

Table 5. Effects of severity and stages on plasma BNP levels in hemorrhagic fever with renal syndrome 


\begin{tabular}{|lll|}
\cline { 1 - 1 } Variables & \multicolumn{1}{l}{} \\
\cline { 1 - 2 } Age, y & 0.07 & 0.7941 \\
\hline Sex (M/F) & 0.74 & 0.3920 \\
\hline Weight, kg & 0.13 & 0.7224 \\
\hline Dialysis & 3.25 & 0.0967 \\
\hline severity & 26.25 & $<.0001$ \\
\hline stages & 19.08 & $<.0001$ \\
\hline severity* stages & 9.77 & $<.0001$ \\
\hline
\end{tabular}

Notes: $\mathrm{P}<0.05$ was considered to indicate statistical significance.

Table 6. Clinical determinants of B-type natriuretic peptide (BNP) expression at different stages of hemorrhagic fever with renal syndrome 


\begin{tabular}{|c|c|c|c|c|c|c|c|c|}
\hline \multirow[t]{2}{*}{ Stage } & \multirow[t]{2}{*}{ Variables } & & \multicolumn{3}{|c|}{ Univariate analysis } & \multicolumn{3}{|c|}{ Multivariate analysis } \\
\hline & & & $\beta$ & $t$ & $P$ & $\beta$ & $t$ & $P$ \\
\hline Febrile stage & Neutrophil count & & 0.82 & 2.42 & 0.0227 & 0.82 & 2.42 & 0.0227 \\
\hline \multirow[t]{4}{*}{ Oliguric stage } & $\begin{array}{l}\text { Creatinine clearance } \\
\text { rate }\end{array}$ & & -19.59 & -2.36 & 0.0277 & & & \\
\hline & Pulse pressure & & 32.74 & 2.61 & 0.0164 & 24.58 & 2.13 & 0.0456 \\
\hline & Disease severity & Severe & 1033.68 & 3.26 & 0.0035 & 840.00 & 2.61 & 0.0166 \\
\hline & & Medium & Ref. & & & & & \\
\hline Transitional & $\begin{array}{l}\text { Creatinine clearance } \\
\text { rate }\end{array}$ & & -5.83 & -3.60 & 0.0007 & & & \\
\hline stage of the & Pulse pressure & & 11.03 & 2.24 & 0.0298 & & & \\
\hline \multirow[t]{5}{*}{ polyuria stage } & Disease severity & Severe & 826.90 & 6.65 & $<.0001$ & 826.00 & 6.65 & $<0.0001$ \\
\hline & & Medium & 295.78 & 2.78 & 0.0074 & 295.78 & 2.78 & 0.0074 \\
\hline & & Mild & Ref. & & & & & \\
\hline & $\mathrm{E} / \mathrm{A}$ & $<1$ & 335.92 & 2.54 & 0.0139 & & & \\
\hline & & $>1$ & Ref. & & & & & \\
\hline Early polyuria & Neutrophil count & & 31.99 & 3.31 & 0.0015 & 19.65 & 2.37 & 0.0206 \\
\hline \multirow[t]{5}{*}{ stage } & Pulse pressure & & 5.25 & 2.65 & 0.0100 & & & \\
\hline & $\begin{array}{l}\text { Creatinine clearance } \\
\text { rate }\end{array}$ & & -1.76 & -2.84 & 0.0058 & & & \\
\hline & Disease severity & Severe & 324.68 & 6.31 & $<.0001$ & 302.45 & 5.61 & $<0.0001$ \\
\hline & & Medium & 165.48 & 3.92 & 0.0002 & 151.82 & 3.52 & 0.0008 \\
\hline & & Mild & Ref. & & & & & \\
\hline $\begin{array}{l}\text { Late polyuria } \\
\text { stage }\end{array}$ & Age & & 1.67 & 2.01 & 0.0495 & 1.67 & 2.01 & 0.0495 \\
\hline
\end{tabular}

Notes: $\beta$ is the parameter estimate: a positive value indicates a positive correlation, and a negative value indicates a negative correlation. $P<0.05$ was considered to indicate statistical significance. "Ref." indicates the reference level. Units: neutrophils, $10^{9} / \mathrm{L}$; creatinine clearance rate, \%; pulse differential pressure, $\mathrm{mm} \mathrm{Hg}$; age, years.

\section{Figures}




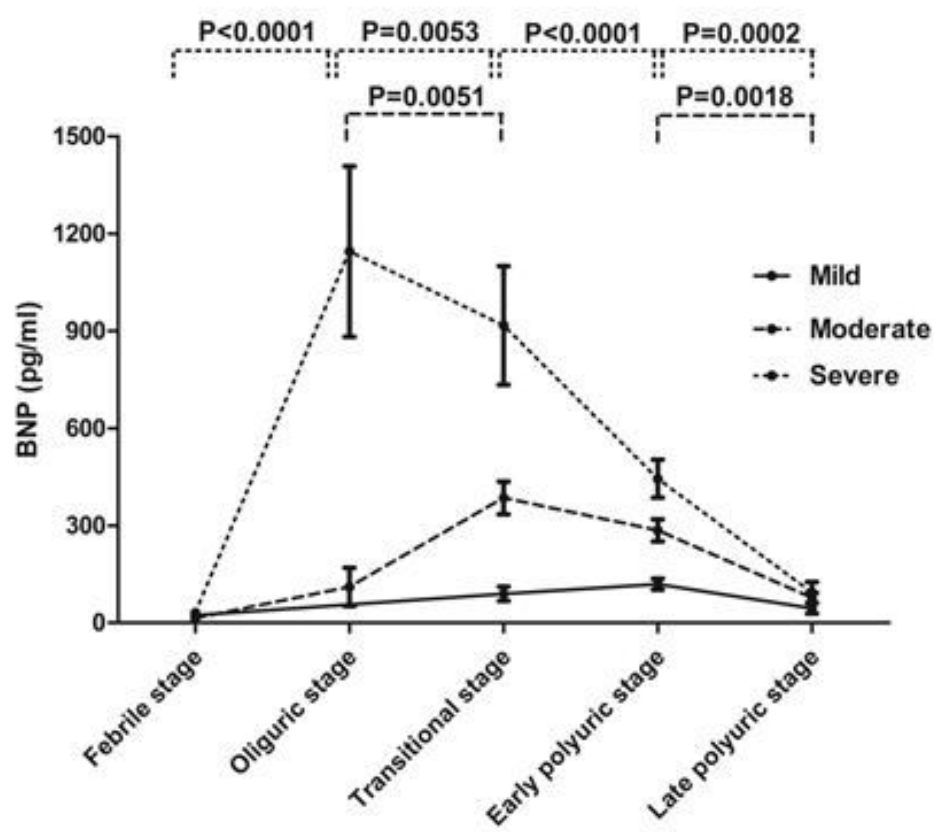

\section{Figure 1}

Dynamic changes in B-type natriuretic peptide (BNP) levels in patients with mild $(n=35)$, moderate $(n=33)$, and severe $(n=18)$ hemorrhagic fever with renal syndrome in the febrile, oliguric, and transitional, early, and late polyuric stage. Circles and bars represent the mean $\otimes$ standard deviation. $P<0.05$ indicates that the BNP levels were significantly different between two adjacent stages. Mild HFRS, solid line; moderate HFRS, dashed line; and severe HFRS, dotted line.

\section{Supplementary Files}

This is a list of supplementary files associated with this preprint. Click to download.

- Supplementary2.docx

- Supplementary1.docx 